JURNAL EXPLORE IT!

Vol. 10 No. 1 - Juni 2018

p-ISSN 2086-3489 (Print)- e-ISSN 2549-354X (Online)

Avaiable online at

http://jurnal.yudharta.ac.id/v2/index.php/EXPLORE-IT/

\title{
PREDIKSI STOK OBAT MENGGUNAKAN METODE RADIAL BASIS FUNCTION NETWORK STUDI KASUS GUDANG FARMASI KESEHATAN PUSKESMAS RACI
}

\author{
${ }^{1}$ M. Saiful Arif \\ ${ }^{1}$ Program Studi Teknik Informatika, Fakultas Teknik \\ ${ }^{1}$ Universitas Yudharta Pasuruan \\ ${ }^{1}$ Email :saifularif2358@gmail.com
}

\begin{abstract}
ABSTRAK
Kesehatan merupakan hal yang penting dari setiap manusia untuk menjalankan aktifitas tanpa ada kendala suatu penyakit. Penykit merupakan suatu kondisi fisik dalam tubuh manusia yang tidak normal yang sangat menggangu pada penderita. Jenis penyakit yang sering ditakuti oleh setiap manusia yaitu penyakit kronis butuh adanya penanganan yang perlu di perhatikan. Obat merupakan suatu zat kimia yang penting untuk media perawatan. Pada bagian farmasi puskesmas raci sering terjadinya kekosongan stok obat dan membutukan waktu lama karena sistem yang digunakan masih menggunakan manual. Oleh karena itu, pada penelitian ini bertujuan untuk mengetahui hasil prediksi dari persedian stok obat dengan menggunakan metode Radial Basis Function Network. Radial Basis Function Network yaitu sebuah arsitektur dari jaringan syaraf tiruan yang terdiri dari input, hidden, dan output layer. Akan tetapi proses input ke hidden perlu digunakan algoritma K-Means. Penelitian ini untuk mengetahui nilai error RMSE dari presiksi stok obat metode Radial Basis Function Network. Hasil prediksi tingkat error yang didapat untuk obat ambroxol berjumlah 0,246, obat amoksisillin berjumlah 0,297, obat anti influenza berjumlah 0,319, obat asam mefenamat berjumlah 0,313, dan obat deksametason berjumlah 0,373.
\end{abstract}

Kata Kunci : prediksi, stok obat, radial basis function network, rmse

\section{PENDAHULUAN}

Obat merupakan zat yang bisa digunakan sebagai media perawatan dalam mengatasi penyakit, serta mengubah proses kimia yang ada ditubuh manusia. Menurut (Tjay \& Rahatdja, 2015) semua zat baik dalam kimiawi, hewani, maupun nabati terdapat dosis layak untuk menyembuhkan, meringankan dan mencegah dalam penyakit.

UPTD Kesehatan Puskesmas Raci sebuah unit pelayanan kesehatan yang bergerak dibidang jasa dalam hal pelayanan kesehatan kepada masyarakat. Pada bagian gudang farmasi puskesmas sistem yang digunakan untuk menghitung stok obat masih menggunakan sistem manual dimana setiap kali pendataan obat menggunakan dengan cara penghitungan dan pendataan obat satu persatu sehingga mengakibatkan masalah dalam suatu sistem akan terjadi kekosongan obat serta membutuhkan waktu lama.

Dengan pesatnya teknologi saat ini teknik data mining serta didukung oleh beberapa metode dapat memberikan solusi untuk mengatasi permasalahan yang berkaitan dengan sebuah prediksi dalam pengambil sebuah keputusan untuk menentukan hasil yang akurat dan cepat terdeteksi dari persediaan stok. 
Bebrapa penelitian sebelumya diantaranya, (Maidarli, 2011) mengusulkan metode Rough Set menyatakan bahwa metode Rough set dapat memecahkan suatu permasalahan dalam proses pengontrolan penghitungan, dan bisa lebih cepat serta optimal dalam memprediksi stok obat agar mendapatkan rule-rule yang singkat dan tepat dalam satu tabel. (Yanti, 2011)mengusulkan penerapan metode Neural Network Backpropagation menyatakan bahwa metode Neural Network Backpropagation sanangat bagus untuk sebuah prediksi metode ini memiliki kekuatan dalam dasar matematis, objektif dan memiliki algoritma yang bisa mendapatkan bentuk persamaan serta memiliki nilai koefisien dalam formula dengan meminimalkan hasil kuadrat galat yang error melalui model yang dikembangkan (training set).(Rwanda, Nikentari, \& Uperati, 2018) mengusulkan metode Radial Basis Function Neural Network (RBFNN) untuk memprediksi kecepatan arus laut hasil dari penelitian tersebut menyipulkan bahwa metode Radial Basis Function Neural Network (RBFNN) menghasilkan nilai MAPE rata-rata 34\%dengan nilai akurasi rata-rata $66 \%$ serta pada pengujian menggunakan 5 center yangmenghasilkan nilai MAPE rata-rata 53\% dengan nilai akurasi rata-rata $47 \%$.

Hasil dari penelitian ini diharapkan dapat bertujuan untuk mengtahui dari penerapan Radial Basis Function Network dalam memprediksi stok obat.Mengetahui hasil dari error yang diperoleh Radial Basis Function Network untuk memprediksi stok obat. Serta diharapkan bermanfaat untuk membantu bagian gudang farmasi puskesmas untuk mengetahui kapan terjadi kehabisan obat. Membantu bagian gudang farmasi puskesmas supaya tidak terjadi keterlambatan dalam proses penyetokan obat.

\section{METODE PENELITIAN}

Tahapan penelitian merupakan sekumpulan kegiatan yang ditempuh oleh peneliti dengan menurut prosedur dan jalanya proses harus benar serta akurat, sehingga dalam hasil penelitiannya bisa dicapai serta diyakini dengan terbukti kebenaran dan dapat dipercaya secara ilmiah.

Sesuai dengan definisi penelitian seperti yang disebutkan bahwa kegiatan penelitian dilaksanakan secara terencana, teratur, dan sistematis. Untuk itu kegiatan penelitian dilaksanakan dalam beberapa tahap secara garis besar sebagai berikut.

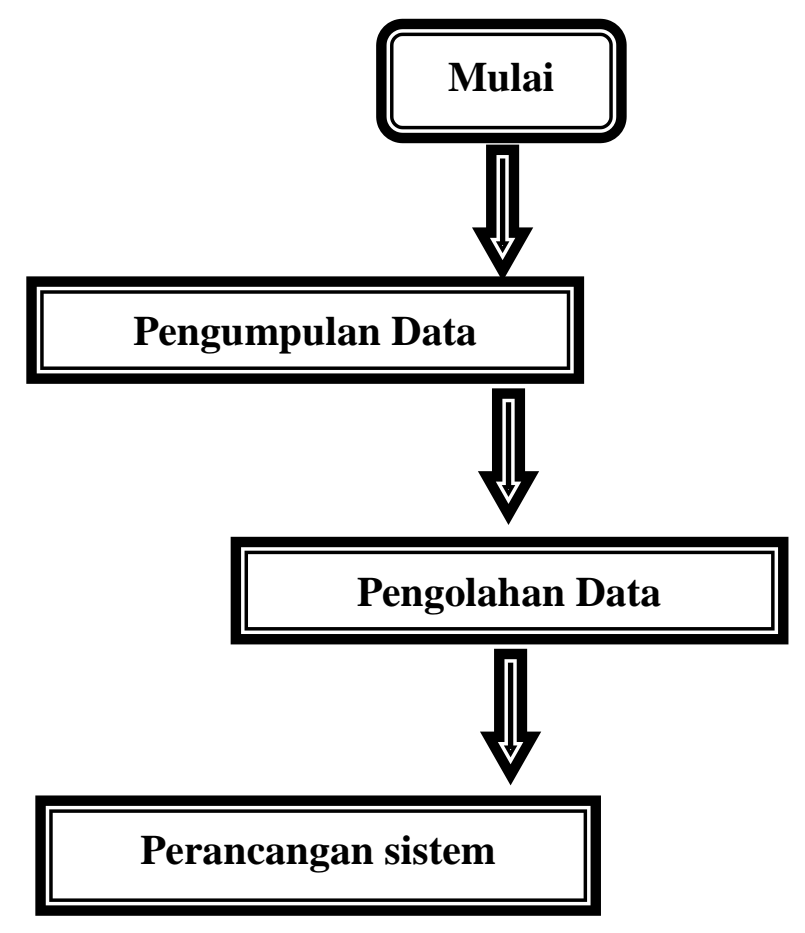




\section{Gambar 3.1 Tahapan penelitian}

1. Pengumpulan data dilakukan untuk memperoleh suatu informasi yang dibutuhkan untuk mencapai tujuan dari peneliti. Pengumpulan data bukan hanya sekedar mengmbil data sampel yang ada, tetapi diharuskan untuk mampu dalam mendeskripsikan data yang ada serta memiliki kontribusi terhadap pengetahuan. Data yang di makasud harus memberikan penjelasan, hubungan, prediksi, estimasi dan teori (Dawson, 2009).

2. Pengolahan data merupakan suatu proses untuk memperoleh data ringkasan berdasarkan data mentah, dari data mentah yang sudah dikumpulkan oleh peneliti kemudian diolah. pengelolahan data merupakan hal yang sangat penting dalam melakukan penelitian guna untuk memperlancar pada proses penelitian.

3. perancangan sistem adalah sebuah proses yang menentukan bagaimana suatu sistem akan menyelesaikan apa yang akan dilakukan pada penelitian ini.Dalam perancangan ini bertujuan untuk menghitung hasil akurasi menggunakan metode radial basis function neural nentwork. Untuk lebih jelasnya bisa dilihat pada gambar 3.2

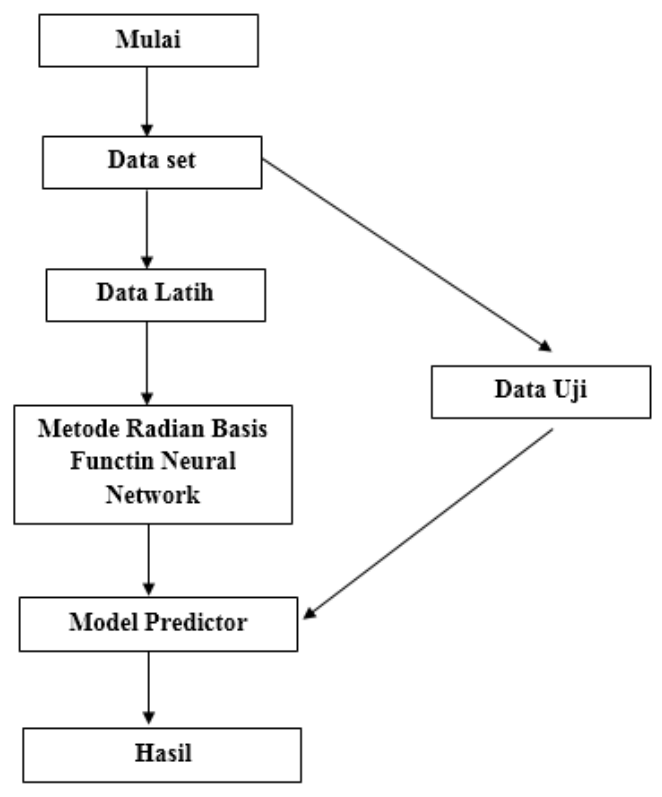

Gambat 3.2 Flowchart perancangan system

Perancangan sistem yang ditunjukkan pada gambar 3.3 dimulai dari data set dipecah menjad dua bagian yaitu data latih dan data uji kemudian dari data latih di proses menggunakan metode radial basis function neural nentwork setelah di proses sehingga menjadi model predictor (model yang digunakan untuk memprediksi nilai), sedangkan dari data uji langsung oleh model predictor, setelah itu dihitung tingkat error.

\section{HASIL DAN PEMBAHASAN}


Data yang digunakan merupakan data penyetokan obat pada gudang farmasi puskesmas raci yang sudah diolah oleh peneliti dipilah dari setiap obat untuk penyetokan selama 2 tahun mulai 2016 sampai 2017.

Tabel 1 Dataset penyetokan obat selama tahun 2016-2017

\begin{tabular}{|c|c|c|c|c|c|c|}
\hline Tahun & Bln & Ambroxol & Amoksisillin & $\begin{array}{c}\text { Asam } \\
\text { Mefenamat }\end{array}$ & $\begin{array}{c}\text { Anti } \\
\text { Influenza }\end{array}$ & Deksametason \\
\hline 2016 & 1 & 900 & 25800 & 18600 & 8300 & 7690 \\
\hline 2016 & 2 & 400 & 21150 & 15000 & 7100 & 4590 \\
\hline 2016 & 3 & 600 & 17750 & 11600 & 4100 & 2390 \\
\hline 2016 & 4 & 400 & 22650 & 11800 & 10700 & 11390 \\
\hline 2016 & 5 & 50 & 17700 & 6900 & 3700 & 6890 \\
\hline 2016 & 6 & 300 & 8460 & 800 & 2500 & 5690 \\
\hline 2016 & 7 & 100 & 35060 & 2500 & 2400 & 8440 \\
\hline 2016 & 8 & 400 & 31760 & 2900 & 8900 & 6240 \\
\hline 2016 & 9 & 500 & 25860 & 16900 & 9500 & 2140 \\
\hline 2016 & 10 & 550 & 20290 & 9600 & 4800 & 9640 \\
\hline 2016 & 11 & 300 & 16300 & 6300 & 7300 & 7100 \\
\hline 2016 & 12 & 100 & 10700 & 800 & 100 & 3200 \\
\hline 2017 & 1 & 400 & 4900 & 15200 & 10300 & 5800 \\
\hline 2017 & 2 & 400 & 19150 & 18000 & 6900 & 4500 \\
\hline 2017 & 3 & 600 & 15750 & 15700 & 5900 & 8700 \\
\hline 2017 & 4 & 600 & 20650 & 14300 & 4700 & 3300 \\
\hline 2017 & 5 & 500 & 15700 & 9700 & 7500 & 7900 \\
\hline 2017 & 6 & 300 & 6460 & 3800 & 5900 & 2400 \\
\hline 2017 & 7 & 750 & 33060 & 9000 & 9600 & 10000 \\
\hline 2017 & 8 & 200 & 29760 & 17700 & 8600 & 10000 \\
\hline 2017 & 9 & 500 & 23860 & 13200 & 3800 & 10000 \\
\hline 2017 & 10 & 550 & 18290 & 5500 & 2700 & 8600 \\
\hline 2017 & 11 & 200 & 14300 & 12200 & 2400 & 4700 \\
\hline 2017 & 12 & 100 & 8700 & 1000 & 100 & 2000 \\
\hline
\end{tabular}

Kemudian dilakukan pengujian terhadap model yang digunakan pada radial basis function network. Pengujian akan dilakukan dengan menggunakan $k$-fold cross validation dan confunsion matrix. Jumlah data sebanyak 12 kemudian dibagi menjadi 10 subset, yaitu : fold 1, fold 2, fold 3, fold 4 , fold 5, fold 6, fold 7, fold 8, fold 9, fold 10. Jadi penelitian akan dilkukan berulang-ulang. Pada setiap pengulangan, 9 fold subset akan dijadikan data latih dan 1 fold subset akan dijadikan data uji. Proses pengulangan akan dilakukan sebanyak 10 kali hingga seluruh fold akan pernah berperan sebagai data latih dan data uji. Pebagian fold subset data dapat diperhatikan pada Tabel 4.2

Tabel 4.2 Pembagian data latih dan data uji dengan 10 fold validasi

\begin{tabular}{|c|c|c|}
\hline Subset & $\begin{array}{c}\text { index data } \\
\text { latih }\end{array}$ & $\begin{array}{c}\text { index data } \\
\text { uji }\end{array}$ \\
\hline fold-1 & $3-12$ & $1-2$ \\
\hline fold-2 & $1-2,5-12$ & $3-4$ \\
\hline fold-3 & $1-4,6-12$ & 5 \\
\hline fold-4 & $1-5,7-12$ & 6 \\
\hline fold-5 & $1-6,8-12$ & 7 \\
\hline fold-6 & $1-7,9-12$ & 8 \\
\hline
\end{tabular}


JURNAL EXPLORE IT!

Vol. 10 No. 1 - Juni 2018

p-ISSN 2086-3489 (Print)- e-ISSN 2549-354X (Online)

Avaiable online at http://jurnal.yudharta.ac.id/v2/index.php/EXPLORE-IT/

\begin{tabular}{|c|c|c|}
\hline fold-7 & $1-8,10-12$ & 9 \\
\hline fold-8 & $1-9,11-12$ & 10 \\
\hline fold-9 & $1-10,12$ & 11 \\
\hline fold-10 & $1-11$ & 12 \\
\hline
\end{tabular}

Tahapan Perhitungan manual dengan sampel stok obat Ambroxol mrnggunakan metode radial basis function network.

Tabel 4.3 Data awal stok obat ambroxol

\begin{tabular}{|c|c|c|}
\hline $\mathrm{n}$ & $\mathrm{x} 1$ & $\mathrm{x} 2$ \\
\hline 1 & 1 & 0.058823529 \\
\hline 2 & 0.411764706 & 0.411764706 \\
\hline 3 & 0.647058824 & 0.411764706 \\
\hline 4 & 0.411764706 & 0.647058824 \\
\hline 5 & 0 & 0.647058824 \\
\hline 6 & 0.294117647 & 0.529411765 \\
\hline 7 & 0.058823529 & 0.294117647 \\
\hline 8 & 0.411764706 & 0.823529412 \\
\hline 9 & 0.529411765 & 0.176470588 \\
\hline 10 & 0.588235294 & 0.529411765 \\
\hline 11 & 0.294117647 & 0.588235294 \\
\hline
\end{tabular}

\begin{tabular}{|l|l|c|c|c|}
\hline & & \multicolumn{2}{c|}{ n } & \multicolumn{2}{c|}{ centroid } \\
\hline & Cluster 1 & $1,2,3,4,5,6$ & 0.46 & 0.45 \\
\hline Cluster 2 & $7,8,9,10,11,12$ & 0.32 & 0.43 \\
\hline 12 & 0.058823529 & 0.176470588 &
\end{tabular}

Pada tabel diatas terdapat dataset obat ambroxol selama 2 tahun yang sudah dinormalisasi kan kemudian dihitung menggunakan metode radial basis function network. berikut merupakan langkahlangkah perhitungan diantaranya :

Tabel 4.4Hasil pencarian centroidambroxol

Dilakukan pengecekan apakah tiap data sudah berada tepat di clusternya masingmasing dengan mencari jarak tersebut terhadap kedua centroid dan kemudian membandingkannya. 
Rumus mencari jarak

$$
\sqrt{\left(X_{1}-C_{1}\right)^{2}+\left(X_{2}-C_{2}\right)^{2}}
$$

Tabel 4.5Perbandingan jarak anggota cluster 1 ambroxol

\begin{tabular}{|c|c|c|c|}
\hline \multicolumn{4}{|c|}{ Cluster 1 } \\
\hline $\mathrm{n}$ & jarak ke c-1 & jarak ke c-2 & \\
\hline 1 & 0.67 & 0.77 & Ya C1 \\
\hline 2 & 0.06 & 0.09 & Ya C1 \\
\hline 3 & 0.19 & 0.32 & Ya C1 \\
\hline 4 & 0.20 & 0.23 & Ya C1 \\
\hline 5 & 0.50 & 0.39 & Bukan C1 \\
\hline 6 & 0.18 & 0.10 & Bukan C1 \\
\hline
\end{tabular}

Perluupdate ulang centroid cluster 1 karna data nomer 5 dan 6 bukan termasuk anggota cluster 1

Tabel 4.6Perbandingan jarak anggota cluster 2 obat ambroxol

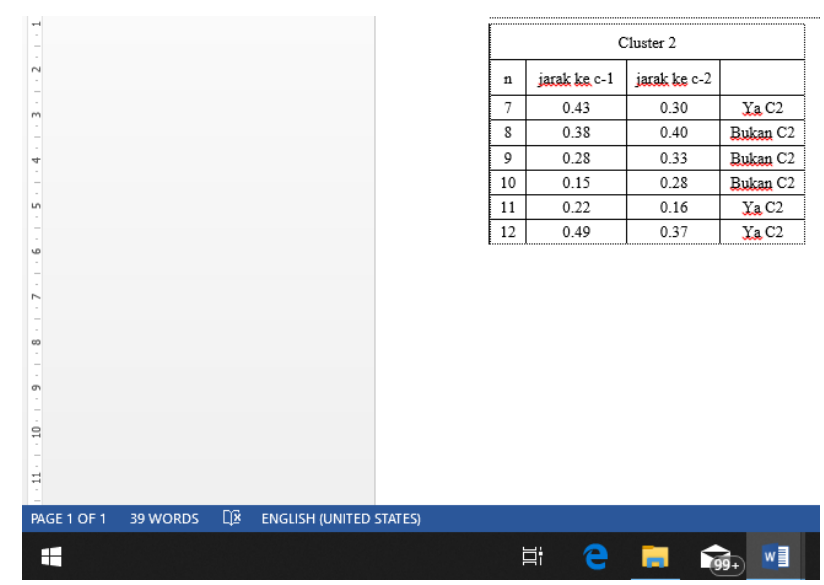

Perluupdate ulang centroid cluster 2 karna data nomer 8,9 dan 10 bukan termasuk anggota cluster 2

Tabel 4.7Hasil update pencarian centroid ambroxol

\begin{tabular}{|c|c|c|c|}
\hline & $\mathrm{n}$ & \multicolumn{2}{|c|}{ centroid } \\
\hline Cluster 1 & $1,2,3,4,8,9,10$ & 0.57 & 0.44 \\
\hline Cluster 2 & $5,6,7,11,12$ & 0.14 & 0.45 \\
\hline
\end{tabular}

Dilakukan pengecekan ulang apakah tiap data sudah berada tepat di clusternya masing-masing dengan mencari jarak tersebut terhadap kedua centroid dan kemudian membandingkannya.

Tabel 4.8 Hasilupdate perbandingan jarak anggota cluster 1

Cluster 1 


\begin{tabular}{|c|c|c|c|}
\hline $\mathrm{n}$ & jarak ke c-1 & jarak ke c-2 & \\
\hline 1 & 0.57 & 0.94 & Ya C1 \\
\hline 2 & 0.16 & 0.27 & Ya C1 \\
\hline 3 & 0.08 & 0.51 & Ya C1 \\
\hline 4 & 0.26 & 0.34 & Ya C1 \\
\hline 8 & 0.42 & 0.46 & Ya C1 \\
\hline 9 & 0.26 & 0.47 & Ya C1 \\
\hline 10 & 0.09 & 0.45 & Ya C1 \\
\hline
\end{tabular}

Setelah dilakukan Update ulang tenyata anggota cluster 1 sudah berada di posisi yang tepat yaitu berjumlah 7 anggota diantanya no. 1, 2, 3, 4, 8, 9, dan 10 .

Tabel 4.9 Hasilupdate perbandingan jarak anggota cluster 2

\begin{tabular}{|c|c|c|c|}
\hline \multicolumn{4}{|c|}{ Cluster 2 } \\
\hline $\mathrm{n}$ & jarak ke c-1 & jarak ke c-2 & \\
\hline 5 & 0.61 & 0.24 & Ya C2 \\
\hline 6 & 0.29 & 0.17 & Ya C2 \\
\hline 7 & 0.53 & 0.17 & Ya C2 \\
\hline 11 & 0.32 & 0.21 & Ya C2 \\
\hline 12 & 0.58 & 0.28 & Ya C2 \\
\hline
\end{tabular}

Setelah dilakukan Update tenyata anggota cluster 2 sudah berada di posisi yang tepat yaitu berjumlah 5 anggota diantanya no. 5, 6, 7, 11, dan 12 .

Menghitung variance menggunakan rumus :

$$
\begin{aligned}
& \frac{\text { Total jarak cluster }}{\text { ang gota }}=\text { Hasil } \\
& \sigma C_{1}=\frac{1,85}{7}=0,26 \\
& \sigma C_{2}=\frac{1,08}{5}=0,22
\end{aligned}
$$

Learning rate $($ rasio pembelajaran $)(\alpha)=0,1$

Target error $=0,001$

Maksimum iterasi $=1000$

Inisialisasi parameter

$$
\begin{aligned}
& \text { a. Bobot awal dari input ke hidden } \\
& w_{11}=0,11 \\
& w_{12}=0,12 \\
& w_{21}=0,21
\end{aligned}
$$


$w_{22}=0,22$

b. Bias awal dari input ke hidden

$$
\begin{aligned}
& b_{1}=0,31 \\
& b_{2}=0,59
\end{aligned}
$$

c. Bobot awal dari hidden ke output

$$
\begin{aligned}
& w_{1}=0,32 \\
& w_{2}=0,34
\end{aligned}
$$

d. Bias awal dari hidden ke output

$$
b_{0}=0,59
$$

Hitungradial basis function network (RBFN)

a. Hitung hidden value / nilai tersembunyi (Z) dari input ke hidden 1 menggunakan rumus :

$$
\begin{aligned}
& Z_{\text {in_1 }}=\left(w_{11} \cdot x_{1}\right)+\left(w_{21} \cdot x_{2}\right)+b_{1} \\
& =(0.11 * 65)+(0,21 * 0,41)+0,31 \\
& =0,470
\end{aligned}
$$

b. Hitung hidden value / nilai tersembunyi (Z) dari input ke hidden 2 menggunakan rumus :

$$
\begin{aligned}
& Z_{\text {in_2 }}=\left(w_{12} \cdot x_{1}\right)+\left(w_{22} \cdot x_{2}\right)+b_{2} \\
& =(0.12 * 65)+(0,22 * 0,41)+0,59 \\
& =0,576
\end{aligned}
$$

c. Hitung nilai $\mathrm{Z}$ menggunakan fungsi aktifasi Gaussian $(R B F)$

$$
\begin{aligned}
& Z_{1}=\exp \left(\frac{I I z_{i}-c_{i} I I^{2}}{2 * \sigma c_{1}^{2}}\right) \\
& =\exp \left(\frac{-\sqrt{\left(Z_{i n_{1}}-C_{1 a}\right)^{2}+\left(Z_{i n_{2}}-C_{1 b}\right)^{2}}}{2 * \sigma c_{1}^{2}}\right) \\
& =\exp \left(\frac{-\sqrt{(0,470-0,57)^{2}+(0,576-0,44)^{2}}}{2 * 0,26^{2}}\right) \\
& =0,091 \\
& Z_{2}=\exp \left(\frac{I I z_{i}-c_{i} I I^{2}}{2 * \sigma c_{2}^{2}}\right)
\end{aligned}
$$




$$
\begin{aligned}
& =\exp \left(\frac{-\sqrt{\left(Z_{\text {in_ } 1}-C_{2 a}\right)^{2}+\left(Z_{\text {in } \_2}-C_{2 b}\right)^{2}}}{2 * \sigma c_{2}^{2}}\right) \\
& =\exp \left(\frac{-\sqrt{(0,470-0,14)^{2}+(0,576-0,45)^{2}}}{2 * 0,22^{2}}\right) \\
& =0,008
\end{aligned}
$$

d. Hitung nilai Y input

$$
\begin{aligned}
& Y_{\text {in }}=\left(w_{1} \cdot z_{1}\right)+\left(w_{2} \cdot z_{2}\right)+b_{0} \\
& =(32 * 0,091)+(0,34 * 0,008)+0,59 \\
& =0,182
\end{aligned}
$$

e. Hitung nilai Y output

$$
\begin{aligned}
& Y_{\text {out }}=\frac{1}{1+\exp ^{Y_{\text {in }}}} \\
& =\frac{1}{1+\exp ^{0,182}} \\
& =0,545
\end{aligned}
$$

f. Hitung nilai error

$$
\text { error }=Y-Y_{\text {out }}
$$

$$
=0,65-0,545=0,10
$$

Update parameter

a. Update bobot input ke hidden

$$
\begin{aligned}
& w_{11}=w_{11}-\left(\alpha \cdot y \cdot x_{1}\right) \\
& =0,11-(0,1 * 0,65 * 0,65) \\
& =0,07 \\
& w_{12}=w_{12}-\left(\alpha \cdot y \cdot x_{1}\right) \\
& =0,12-(0,1 * 0,65 * 0,65) \\
& =0,08 \\
& w_{21}=w_{21}-\left(\alpha \cdot y \cdot x_{2}\right) \\
& =0,21-(0,1 * 0,65 * 0,41) \\
& =0,18 \\
& w_{22}=w_{22}-\left(\alpha \cdot y \cdot x_{2}\right) \\
& =0,22-(0,1 * 0,65 * 0,41) \\
& =0,19
\end{aligned}
$$

b. Update Bias Input ke Hidden

$$
\begin{aligned}
& b_{1}=b_{1}-(\alpha \cdot y) \\
& =0,31-(0,1 * 0,65) \\
& =0,25
\end{aligned}
$$




$$
\begin{aligned}
& b_{2}=b_{2}-(\alpha \cdot y) \\
& =0.59-(0,1 * 0,65) \\
& =0,52
\end{aligned}
$$

c. Update bobot hidden ke output

$w_{1}=w_{1}-\left(\alpha \cdot y \cdot z_{1}\right)$

$=0,32-(0,1 * 0,65 * 0,091)$

$=0,31$

$w_{2}=w_{2}-\left(\alpha \cdot y \cdot z_{2}\right)$

$=0,34-(0,1 * 0,65 * 0,008)$

$=0,34$

d. Update Bias ke output

$$
b_{0}=b_{0} \cdot \alpha \cdot y=0,59 * 0,1 * 0,65=0,09
$$

Perhitungan otomatis dengan menggunakan aplikasi WEKE untuk meprediksi target stok obat pada bulan Januari 2018. hasil prediksi ditunjukkan pada gambar berikut :

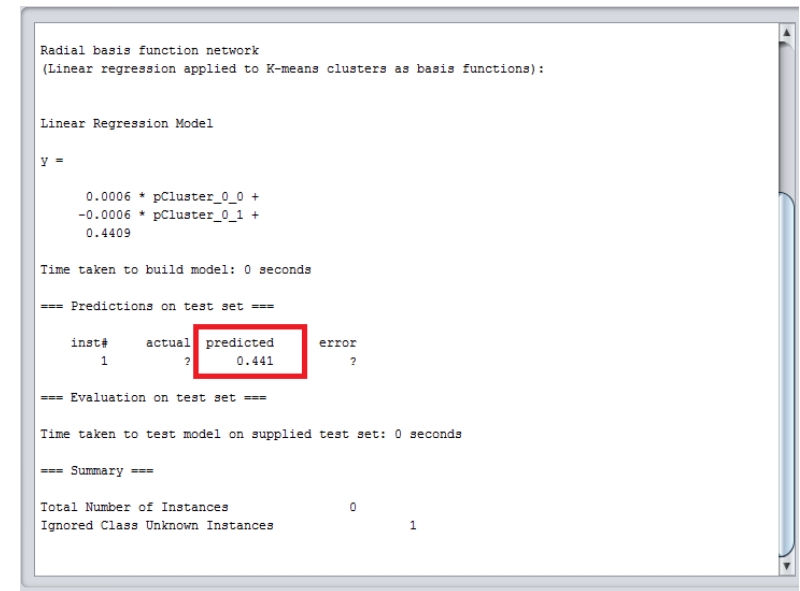

\section{Gambar 4.2 hasil prediksi obat ambroxol}

Perhitungan dari perediksi yang di hasilkan metode RBF Network untuk mengetahui tingkat errornya berikut merupakan perhitungan manual untuk mencari nilai RMSE menggunakan rumus :

$$
\sqrt{\frac{\left(a_{1}\right)^{2}+\left(a_{1}\right)^{2}+\left(a_{1}\right)^{2}+\left(a_{1}\right)^{2} \ldots \ldots \ldots n}{n}}
$$

1. Mencari nilai error dengan menggunakan rumus :

Data aktual - Data prediksi $=$ nilai error

Hasil perhitungan nilai error bisa dilihat pada tabel 4.51

Tabel 4.10 Nilai error pada prediksi stok obat Ambroxol

\begin{tabular}{|c|c|c|c|}
\hline Fold & aktual & prediksi & error \\
\hline fold-1 & 0.294 & 0.388 & 0.094 \\
\hline
\end{tabular}




\begin{tabular}{|c|c|c|c|}
\hline & 0.412 & 0.391 & -0.021 \\
\hline \multirow{2}{*}{ fold-2 } & 0.529 & 0.359 & -0.17 \\
\cline { 2 - 4 } & 0.647 & 0.292 & -0.355 \\
\hline fold-3 & 0.059 & 0.466 & 0.407 \\
\hline fold-4 & 0.647 & 0.444 & -0.203 \\
\hline fold-5 & 0.529 & 0.519 & -0.01 \\
\hline fold-6 & 0.412 & 0.452 & 0.04 \\
\hline fold-7 & 0.176 & 0.445 & 0.269 \\
\hline fold-8 & 0.176 & 0.475 & 0.299 \\
\hline fold-9 & 0.824 & 0.412 & -0.412 \\
\hline fold-10 & 0.588 & 0.429 & -0.159 \\
\hline
\end{tabular}

2. Setelah diketahui nilai error kemudian menghitung nilai RMSE

$$
\begin{gathered}
\sqrt{\frac{(0,09)^{2}+(0,021)^{2}+(0,17)^{2} \ldots(0,159)^{2}}{12}} \\
=\sqrt{\frac{0,729547}{12}}=\sqrt{0,060795583}=0,246
\end{gathered}
$$

\section{PENUTUP}

\subsection{KESIMPULAN}

1. Hasil prediksi dari persedian stok obat dengan menggunakan metode Radial Basis Function Network mampu meningkatkat tingkat akurasi.

2. Hasil prediksi tingkat error yang didapat untuk obat ambroxol berjumlah 0,246 , obat amoksisillin berjumlah 0,297 , obat anti influenza berjumlah 0,319 , obat asam mefenamat berjumlah 0,313 , dan obat deksametason berjumlah 0,373.

\subsection{SARAN}

1. dibutuhkan metode lain untuk membandingkan metode RBF dalam tingkat akurasi dan mengurangi error.

\section{DAFTAR PUSTAKA}

Dawson, C. W. (2009). Projects in Computingand Information Systems. Information Systems journal.

Haykin, S. (2009). Nueral Networks and Learning Machines. United State of America: Pearson.

Hermawati, F. A. (2013). Data Mining. Yogyakarta: Andi.

Julianto, W., Yunitarini, R., \& Sophan, M. K. (2014). ALGORITMA C4.5 UNTUK PENILAIAN KINERJA KARYAWAN. ISSN, 33-39. 
Maidarli, F. (2011). SISTEM PREDIKSI STOK OBAT DENGAN MENGGUNAKAN METODE ROUGH SET (Studi Kasus : Apotek X Bangkinang-Riau).

Permatasari, A. I., \& Mahmudy, W. F. (2015). Pemodelan Regresi Linear dalam Konsumsi Kwh Listrik di Kota Batu Menggunakan Algoritma Genetika. DORO: Repository Jurnal Mahasiswa PTIIK Universitas Brawijaya, 1-9.

Rwanda, W. W., Nikentari, N., \& Uperati, A. (2018). PREDIKSI KECEPATAN ARUS LAUT PERAIRAN PULAU BINTAN MENGGUNAKAN RADIAL BASIS FUNCTION NEURAL NETWORK (RBFNN). 1-6.

Sutojo, T., Mulyanto, E., \& Suhartono, V. (2011). Kecerdasan Buatan. Yogyakarta: Andi.

Tjay, T. H., \& Rahatdja, K. (2015). Obat-Obat Penting Edisi Ketujuh. Jakarta: Elex Media Komputindo.

Yanti, N. (2011). PENERAPAN METODE NEURAL NETWORK DENGAN STRUKTUR BACKPROPAGATION UNTUK PREDIKSI STOK OBAT DI APOTEK (STUDI KASUSU : APOTEK ABC). Seminar Nasional Aplikasi Teknologi Informasi 2011 (SNATI 2011), 15-2 